\section{Commentary: Subclinical valve thrombosis - are all transcatheter aortic valves created equal?}

\author{
Sajiram Sarvananthan, MBBS, MRCS, and \\ Clifford William Barlow, FRCS(CTh), DPhil
}

Transcatheter aortic valve insertion (TAVI) technology presents new opportunities but also new challenges, including subclinical valve thrombosis (SCVT). In this edition of the Journal, Woldendorp and colleagues ${ }^{1}$ report a meta-analysis investigating SCVT after TAVI focusing on prevalence, predisposing factors, management, and consequences. Twelve studies that screened for SCVT using multidetector computed tomography (MDCT) were included comparing stroke risk between patients with SCVT and those without, as well as the effects of antiplatelet therapy and oral anticoagulation (OAC) on preventing SCVT.

From 3456 patients, $398(11.5 \%)$ showed evidence of SCVT. Portico valves demonstrated the greatest rate of SCVT at 33\% (31 of 95), whereas rates of SCVT in Sapien valves were closer to the mean and CoreValve valves had the lowest incidence of $0.9 \%$ ( 4 of 456). Dual and single antiplatelet therapy was given in $45.5 \%$ and $19.8 \%$ of cases, respectively, and OAC in $28.5 \%$. There were 112 strokes $(3.2 \%)$ with stroke rates more than 2 times greater in patients with SCVT compared with those without, and OAC was superior to antiplatelet therapy in preventing SCVT $(8.8 \%$ vs $15.3 \%)$.

The authors acknowledge several limitations to their study, including different time points for screening for SCVT, factors influencing thromboprophylaxis choice, and that patient-level data were not accessed. Bleeding complications of any antithrombotic regimen were not available and so no comment on safety could be made.

From the Department of Cardiothoracic Surgery, University Hospital Southampton, Southampton, United Kingdom.

Disclosures: Authors have nothing to disclose with regard to commercial support.

Received for publication Feb 7, 2020; accepted for publication Feb 11, 2020; available ahead of print Feb 21, 2020.

Address for reprints: Clifford William Barlow, FRCS(CTh), DPhil, Department of Cardiothoracic Surgery, University Hospital Southampton, Southampton, United Kingdom (E-mail: cliffbarlow@hotmail.com).

J Thorac Cardiovasc Surg 2021;162:1502-3

0022-5223/ $\$ 36.00$

Crown Copyright $(2020$ Published by Elsevier Inc. on behalf of The American Association for Thoracic Surgery

https://doi.org/10.1016/j.jtcvs.2020.02.051

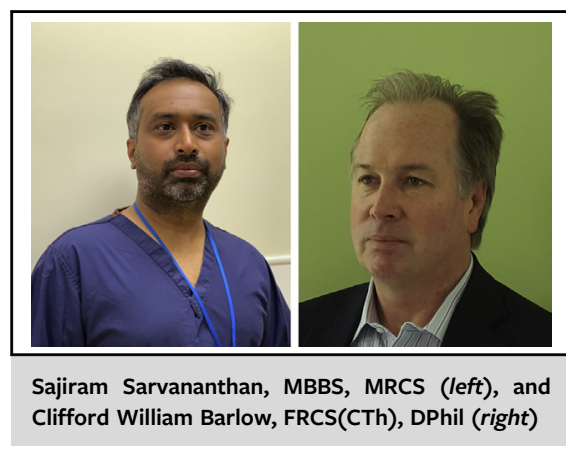

\section{CENTRAL MESSAGE \\ As evidence of subclinical valve thrombosis after transcatheter aortic valve insertion emerges, as well as its consequences and best management, we must not ignore differences between valve types.}

The authors reference 2 large studies involving more than 5000 patients, not included in their meta-analysis because MDCT was not employed for SCVT diagnosis, that showed much lower rates of SCVT at $0.6 \%$ to $0.71 \%$ and also found no association between SCVT and thromboembolic events. ${ }^{2,3}$ Finally, although Portico valves had the greatest incidence of SCVT, correlating valve type to stroke risk was also not possible.

The study is a meta-analysis and must be carefully interrogated to assess whether it contributes more than the "sum of its parts." However, it is provocative in possibly providing evidence of an association between SCVT and stroke after TAVI and also the role of OAC in preventing SCVT. Nevertheless, in addition to the limitations discussed by the authors, there are other important considerations regarding their meta-analysis. All 12 studies included screened for SCVT with MDCT but were otherwise quite diverse in terms of patient numbers developing SCVT, stroke rates, and association between SCVT and stroke. Importantly different TAVI valve types were employed in the 12 studies, for example, those of Chakravarty and colleagues ${ }^{4}$ and Makkar and colleagues ${ }^{5}$ used the Portico valve, with an apparent SCVT rate greater than $30 \%$, in some patients. Would the association of SCVT and stroke still pertain if these 2 studies were excluded from the meta-analysis? Woldendorp and colleagues conclude that SCVT is fairly common after TAVI, suggest SCVT is associated with increased stroke risk, and is most effectively 
prevented with OAC. They suggest that future research focuses on "clinically sound guidelines in the postoperative screening and management of SCVT."

These recommendations are sensible. Implicit in them, however, is that MDCT to assess for SCVT might be appropriate screening for all patients post-TAVI and that OAC is used as preventive therapy for SCVT when we have little information on bleeding complications in this population. Should these recommendations apply to a valve type with an SCVT rate less than $1 \%$ ? The preamble to the US Constitution holds "to be self-evident, that all men are created equal." With regards the diagnosis and management of SCVT after TAVI, should our initial research not be directed to assess whether or not all TAVI valves "are created equal?"

\section{References}

1. Woldendorp K, Doyle MP, Black D, Ng M, Keech A, Grieve S, et al Subclinical valve thrombosis in transcatheter aortic valve implantation: a systematic review and meta-analysis. J Thorac Cardiovasc Surg. 2021;162: 1491-9.e2.

2. Franzone A, Pilgrim T, Haynes AG, Lanz J, Asami M, Praz F, et al. Transcatheter aortic valve thrombosis: incidence, clinical presentation and long-term outcomes. Eur Heart J Cardiovasc Imaging. 2018;19:398-404.

3. Latib A, Naganuma T, Abdel-Wahab M, Danenberg H, Cota L, Barbanti M, et al Treatment and clinical outcomes of transcatheter heart valve thrombosis. Circ Cardiovasc Interv. 2015;8:e001779.

4. Chakravarty T, Søndergaard L, Friedman J, De Backer O, Berman D, Kofoed KF et al; RESOLVE; SAVORY Investigators. Subclinical leaflet thrombosis in surgical and transcatheter bioprosthetic aortic valves: an observational study. Lancet. 2017;389:2383-92.

5. Makkar RR, Fontana G, Jilaihawi H, Chakravarty T, Kofoed KF, de Backer O, et al. Possible subclinical leaflet thrombosis in bioprosthetic aortic valves. $N$ Engl J Med. 2015;373:2015-24. 